\title{
Playful language alternation in an online discussion forum: the example of digital code plays
}

Article

Accepted Version

Original Research Article

Jaworska, S. (2014) Playful language alternation in an online discussion forum: the example of digital code plays. Journal of Pragmatics, 71. pp. 56-68. ISSN 0378-2166 doi:

https://doi.org/10.1016/j.pragma.2014.07.009 Available at https://centaur.reading.ac.uk/37169/

It is advisable to refer to the publisher's version if you intend to cite from the work. See Guidance on citing.

To link to this article DOI: http://dx.doi.org/10.1016/j.pragma.2014.07.009

Publisher: Elsevier

All outputs in CentAUR are protected by Intellectual Property Rights law, including copyright law. Copyright and IPR is retained by the creators or other copyright holders. Terms and conditions for use of this material are defined in the End User Agreement.

$\underline{\text { www.reading.ac.uk/centaur }}$

\section{CentAUR}


Central Archive at the University of Reading

Reading's research outputs online 


\section{Title}

Playful language alternation in an online discussion forum: the example of digital code plays

Author's names and affiliations:

Sylvia Jaworska (University of Reading, UK, corresponding author)

Postal address (corresponding author):

Department of English Language \& Applied Linguistics

University of Reading

Whiteknights

Reading RG6 6AW

UK

Tel: 01183787885

Email address: s.jaworska@reading.ac.uk

\section{Bio-note:}

Sylvia Jaworska is a lecturer in Applied Linguistics in the Department of English Language and Applied Linguistics at the University of Reading. Her main research areas are Discourse Analysis and Corpus Linguistics, especially the application of both methods to investigate discursive strategies in gendered and racist language, and linguistic practices in Computer-Mediated-Communication. Her recent publications include 'On the F-word: a corpus-based analysis of the media representation of Feminism in British and German press discourse' (in Discourse \& Society 2012, with Ramesh Krishnamurthy) and 'Anti-slavic imagery in German radical nationalist discourse' (in Patterns of Prejudice 2011).
Abstract:
This paper explores the linguistic practice of digital code plays in an online discussion forum, used by the community of English-speaking Germans living in Britain. By adopting a qualitative approach of Computer-Mediated Discourse Analysis, the article examines the ways in which these bilinguals deploy linguistic and other semiotic resources on the forum to co-construct humorous code plays. These performances occur in the context of negotiating language norms and are based on conscious manipulations of both codes, English and German. They involve play with codes at three levels: play with forms, meanings, and frames. Although, at first sight, such alternations appear to be used mainly for a comic effect, there is more to this than just humour. By mixing both codes at all levels, the participants deliberately produce aberrant German 'polluted' with English and, in so doing, dismantle the ideology of language purity upheld by the purist movement. The deliberate character of this type of code alternation demonstrates heightened metalinguistic awareness as well as creativity and criticality. By exploring the practice of digital code plays, the current study contributes to the growing body of research on networked multilingualism as well as to practices associated with translanguaging, poly- and metrolingualism.

\section{Keywords:}

Digital Code Plays; Code Switching; Computer Mediated Communication (CMC); Translanguaging; Networked Multilingualism 


\section{Introduction}

This paper investigates the linguistic practice of digital code plays in an online discussion forum used by English-speaking German expatriates living in Britain. Earlier research concerned with communicative practices of bi- or multilingual speakers in digital environments, especially Web 2.0, has revealed a wide variety of strategies these speakers deploy to convey meanings, maintain relationships, and construct offline identity (Georgakopoulou, 1997; Androutsopoulos and Hinnenkamp, 2001; Androutsopoulos, 2006, 2007, 2013; Su 2007; Tseliga, 2007; Barton \& Lee, 2013; Tagg and Seargeant, 2013; Themistocleous, 2013). Bi- or multilingual speakers are interested not only because they are able to draw on more linguistic and semiotic resources than monolingual speakers, but because they often combine and manipulate such multiple resources available to them in productive, innovative, and playful ways (Su, 2007; Androutsopoulos, 2013; Barton and Lee, 2013; Tagg and Seargeant, 2013). This has been demonstrated by exploring practices in two areas: (1) language choice and digital code-switching (Georgakopoulou, 1997; Androutsopoulos and Hinnenkamp, 2001; Androutsopoulos, 2006, 2007, 2013; Themistocleous, 2013); and, (2) writing systems (Su, 2007; Tseliga, 2007; Tagg and Seargeant, 2013). The current study attempts to contribute to such research on the digital practices of bi- and multilinguals by exploring a phenomenon that has not been documented in research, that of digital code plays.

The concept of digital code play was developed when studying online exchanges conducted by German speakers of English on the aforementioned Internet forum. It was quickly noted that these speakers utilise linguistic and other resources available to them to engage in playful alternations of the two codes English and German. This, in many ways, novel linguistic practice goes beyond the use of occasional code switches for the purpose of humour or 'fun with words' identified in research (Woolard, 1988; Stølen, 1992; Siegel, 1995; Androutsopoulos, 2007; Chiaro, 2009; Tsiplakou, 2009; Li 2011) and hence, the traditional notion of code switching cannot account for this. Whereas code switches are mostly well integrated into the morphosyntax and the semantics of another language, the alternations detected in the bilingual online exchanges studied here involve a whole range of grammatical and semantic violations. Despite the violations, they remain understood by the participants. As demonstrated below, code plays have an essentially metalinguistic 
character, as they seem to occur predominantly in the context in which the language norms are negotiated. They involve conscious manipulations of linguistic rules, and are highly contextualised (online) performances based on ad-hoc plays with linguistic material, as such are forms, patterns and rules of the codes available to the users. With this process, the users create new rules of interaction, and interpretation, that go beyond the ostensible purpose of the communicative channel - an online discussion forum, which is essentially designed for information exchange. In this sense, digital code plays can be seen as a practice of networked multilingualism - a term recently suggested by Androutsopoulos (2013: 4) to account for "everything language users do with the entire range of linguistic resources" to communicate in online environments. This notion is much inspired by current thinking on social multilingualism, especially concepts such as metrolingualism (Jørgensen, 2008), polylingualism (Otsuji and Pennycook, 2010) and translanguaging (Li, 2011). Although developed in different contexts, what unites these notions is that they appear to challenge the long assumed one-dimensional relation between language(s), ethnicity and place, and emphasise the fluidity and flexibility of multilingual practices. As these notions reveal, language users, especially in multilingual urban contexts, deploy whatever linguistic and semiotic resources they have at their disposal to fulfil their communicative needs. Regardless of the level of language proficiency, multilinguals engage in various types of translanguaging ranging from code-switching to translation and transliteration to create multilingual bricolages (cf. Tsiplakou and loannidou, 2012) which, consciously or unconsciously, disobey the expected norms of linguistic behaviour such as, for example, the double monolingualism norm or the integrated bilingualism norm. In doing so, multilinguals demonstrate their creativity and criticality, as Li (2011) shows in analysis of translanguaging practices in urban contexts. By creativity, Li understands "the ability to choose between following and flouting the rules (...) including the use of language", whereas criticality demonstrates, among other things, the ability to question "received wisdom" (Li, 2011: 1223). As demonstrated below, the notion of digital code play entails both creativity and criticality. By consciously flouting linguistic and other semiotic rules, the bilingual forum users in the context under study display their creativity, while simultaneously challenging the 'received wisdom' of the ideology of language purity permeating the current language ideological 
debate in Germany (Spitzmüller, 2005, 2007). In line with the current thinking about multilingual practices offline and online (Androutsopoulos, 2013), digital code plays are examples of practices associated with poly- and metrolingualism, as they too disrupt the assumed norm of double monolingualism or separation of languages. The concept of digital code play draws also on the notion of metalanguage (Jaworski et al., 2004) and play frame elaborated by Coates (2007) and Lytra (2007). The concept is also informed by recent studies on language play in virtual environments (Belz and Reinhardt, 2004; Werner, 2004; Tagg and Seargeant, 2013).

The data under scrutiny comes from an online discussion forum Deutsche in London (Germans in London, DiL hereafter), which is extensively used by German expatriates living in the UK. The analysis follows a qualitative approach of ComputerMediated Discourse Analysis (CMDA) adopted in research on language diversity and variation in Computer-Mediated Communication. The term Computer-Mediated Communication (CMC) refers to human to human interactions via networked computers. A distinction is normally drawn between synchronous and asynchronous communication; the former denotes mode of communication where in order to receive messages, both sender and receiver are simultaneously logged in (i.e. real life chats), while the latter does not require real-time interaction (e.g. email). The online exchanges analysed are examples of asynchronous communication.

By undertaking an in-depth qualitative analysis of online exchanges, including instances of digital code plays, the current study demonstrates how this resource is strategically employed by German expatriates living in the UK to convey and negotiate language norms and to express bilingual creativity; the latter is an area that, as $\mathrm{Li}$ (2011) observes, is underexplored in multilingualism research.

The current paper begins by providing a brief overview of research on language alternation in digital environments. Subsequently, the theoretical concepts underpinning the notion of digital code play are elaborated. Distinctive features of code plays are discussed by focusing on how the notion differs from the neighbouring concept of code switching. The third section outlines the research methodology, the context of study and the data set under scrutiny. Section four outlines the main body with four examples of online exchanges interspersed with instances of digital code plays, which are examined to explore the forms and functions of this novel linguistic practice. Section five discusses the results with a 
focus on the role of digital code plays and their ability to convey the metalinguistic discourse online as well as to display performatively participants' bilingual identity.

\section{Switching codes vs. playing with codes: the notion of digital code plays}

Since the notion of digital code plays shares some characteristics, but also differs from, the neighbouring concept of code switching (CS), this section begins by providing a brief overview of research on CS on the Internet. Despite the vast number of studies devoted to CS, there appears to be minimal consensus as to how to define the phenomenon. Following Matras (2009: 101), CS is used here in the broad sense to refer to "the alternation of languages within a conversation".

Since the late 1990s, there is a growing interest in language alternation in multilingual CMC. Drawing on conversational (Auer, 1998) and social-network approaches (Li, et al. 1992), many studies in this area focus on CS, its frequency, forms, and functions in a variety of synchronous and asynchronous communication channels (Paolillo, 1996; Georgakopoulou, 1997; Androutsopoulos and Hinnenkamp, 2001; Androutsopoulos, 2006, 2007, 2013). Whereas early research has identified only limited uses of CS, namely in formulaic expressions (Paolillo, 1996), subsequent studies reveal a much wider repertoire of CS in CMC. For example Georgakopoulou (1997) examines a corpus of private emails written by Greek professionals living in England and shows that alongside style shifts, instances of CS function as the main contextualisation cues and hedging devices used in toning down confrontations or counterbalancing face threats often in a jocular way - a strategy employed for establishing and strengthening solidarity. Similar functions of CS are identified in further studies (Androutsopoulos and Hinnenkamp, 2001; Androutsopoulos, 2006, 2007). Androutsopoulos and Hinnenkamp (2001) investigated CS in Turkish and Greek diasporic chat rooms maintained in Germany. Although in both chat rooms the home languages were the main languages of communication, the data reveals frequent instances of switches into German. These functioned as signals of solidarity, consensus or disagreement. Subsequent research by Androutsopoulos $(2006,2007,2013)$, in the variety of online contexts including social networking sites, provide further evidence for the use of CS as a resource for 
the management of interpersonal relationships; some of the particularly salient uses of CS involve signalling humour and mitigation of potential face threats.

The overall conclusion that emerges from the studies on CS on the Internet indicates that both synchronous and asynchronous forms of multilingual CMC can be a rich site of CS and that the instances of CS are similar but not identical to conversational CS. This conclusion should not be surprising because, as a medium, $\mathrm{CMC}$ is different to speech. While online interactions might resemble spontaneous conversation, the Internet is essentially a written medium and even the most synchronous CMC modes are subject to time delays and can be, at best, described as quasi-synchronous (Dürscheid, 2004). As discussed by Barton and Lee (2013: 26), CMC is essentially a digital space which "is constantly being written". CMC comes with certain affordances, that is, constraints (e.g. a lack of non-verbal cues). Yet, concurrently, it offers a rich set of new possibilities that are consciously exploited by CMC users, often by deploying linguistic and other resources in a creative and sophisticated way. For example, Hinrichs' (2006) observes that the spontaneous and planned nature of CMC contributed to a greater use of symbolic and rhetorical uses of CS in Jamaican CMC, while Tsiplakou (2009) asserts the key role of the new medium, especially its hybridity, in 'doing' bilingualism performatively by means of extensive style-shifting and language mixing. Further, Themistocleous (2013) notes that alongside social conventions, medium-related factors such as 'speak-in-writing' and anonymity facilitate the use of switches into the non-standard regional dialect of Cypriot Greek, in order to perform and switch between different social roles and identities.

One of the main features regularly mentioned in this growing body of research on CS in multilingual CMC is language play and playfulness. For example, Androutsopoulos (2007: 359) observes that playfulness is, in fact, "the most conspicuous aspect" of all the instances of CS regardless of whether they are intended as play or not. Despite the saliency of play in CMC environments (cf. Danet et al., 1997), there has been, to date, little systematic research into the forms and functions of play in multilingual CMC, exception being studies by Belz and Reinhardt (2004), Warner (2004) and Tagg and Seargeant (2013). By analysing online interactions in the context of foreign language teaching, Belz and Reinhardt (2004) stipulate that it is the slower pace of CMC and the opportunity to use CS that 
encourages participants to consciously play with a target language. The medium the Internet - facilitates language play in that it blurs the traditional notion of orality and literacy. In so doing, it becomes "a sort of liminoid contact zone" (Belz and Reinhardt, 2004: 348), in which the traditional rules of communicative practice can be suspended. This suspension can lead to "a subsequent re-negotiation of the rules of linguistic engagement, and it is in this re-negotiation that one finds the room (and the time) for slippage, artifice, burlesque, farce, gimmick, ruse, and play" (Belz and Reinhardt, 2004: 348). Similarly, Warner (2004) examines play with the target language in a synchronous $\mathrm{MOO}^{1}$ and, following Cook (2000), identifies three types of language play: play with the form, play with the content/ concept, and play with the frame. While the first type of play involves a conscious manipulation of morphology, syntax, letters, repetition, and alliteration, the second type is a kind of a semantic play based on combinations of primary word meanings that create new meanings. The final type of play is "largely meta-linguistic and occurs on the level of understanding" (Werner, 2004: 74). It can entail role play, identity play or play with social rules and conventions. This type of play is not essentially "defined by a social impact" but "through play with pieces of discourse" and in so doing, it comes close to Bakhtin's concept of parody (Warner, 2004: 74).

Tagg and Seargeant (2013) study forms of play with writing systems in ThaiEnglish online interactions. The authors begin their analysis with a useful distinction between playfulness and language play. While the former means a general funny or witty spirit in which an activity is conducted, the latter refers to a use of language "which, among other things, includes a focus on linguistic form in communicating meaning" (Tagg and Seargeant, 2013: 196). Tagg and Seargeant note that language play, especially the focus on form, appears a far more prevalent feature of language use than originally thought, and that language play is more likely to occur in cases where participants are involved in negotiating interpersonal meanings rather than exchanging information. With their analysis of Thai-English online exchanges, they demonstrate how participants use multilingual scripts in a playful way to construct interpersonal meanings, as well as social identity as young and international Thais.

\footnotetext{
${ }^{1} \mathrm{MOO}$ is a text-based, multi-user virtual system used for creating text-based virtual realities and adventure games.
} 
The current study attempts to contribute to the growing body of research on multilingual practices on the Internet by illuminating the phenomenon of digital code plays and the role the practice plays in 'doing' bilingualism online. Examples of language alternation studied in research summarised above are mainly switches consisting of single words, phrases or sentences of one language that are well integrated into another. Instances of language alternation that are examined below are of a different kind. They are based on conscious manipulations and playful distortions of linguistic 'material', i.e. forms, patterns and rules underlying the codes available to the users. I refer to this kind of language alternation as digital code plays.

The notion of digital code play draws on the concept of play frame first introduced by Bateson (1972) and further elaborated by Goffman (1974) to account for the ways in which humans organise, categorise and interpret experience. According to Goffman (1974), a frame is a set of shared organisational principles which position actions and events in an interpretative context. Goffman (1974) defines a play frame as a set of principles evoked by cues or metamessages communicating to the participants that what is intended is a play and it should not be taken seriously. The notion of play frame has been used to examine a number of conversational contexts mostly involving humorous and playful interactions between children and adults with children (Lytra, 2007; Aukrust, 2004). Most scholars have, so far, focused on uncovering types of linguistic and other cues that evoke play frames in conversations. Lytra (2007), for instance, analyses constructions of play frames by children of different ethnic origins in a school context in Greece. By drawing on Bauman's (1975) conception of talk as a performance, Lytra further elaborates the notion of play frame, understood as a performance that is "bound by convention", but at the same time, is open to variability and innovation (2007: 18). In introducing a play frame, performers can creatively manipulate language norms and routines to reconfigure social relations and roles, and to make identity claims. Lytra's analysis of instances of playful talk amongst school children demonstrate that alongside teasing, humming or chanting, nicknames are the most common form of playful talk inviting many children to participate.

Coates (2007) looks at humorous talk in informal conversations between friends and family members. Coates observed that humorous talk in a play frame differs 
from conversations based on joke-telling, in that the play frame creates a space when humour emerges organically from the conversation, and is collaboratively constructed by all participants involved. Coates compares such co-constructions to jazz music. Similar to jazz musicians who "co-construct music as they improvise on the theme", participants in playful talk engage spontaneously in a joint activity to create humorous narratives (Coates, 2007: 32). This, in turn, contributes to the creation and maintenance of solidarity. Apart from collaboration which is the prerequisite of playful talk, Coates (2007: 38) identifies five features that "seem to be intrinsically involved in what it means to 'play' conversationally". These are overlapping speech, the co-construction of utterances, repetition, laughter, and metaphor.

Although both of the above studies are directed towards different aims and were conducted in different contexts, they reveal a number of common features as to what play frame entails. Firstly, establishing and maintaining a play frame requires collaboration and spontaneity. Secondly, talk in a play frame is normally a highly contextualised performance that would be difficult to understand outside its interactional context (Coates, 2007). Thirdly, play frame invites variability and innovation, which in turn can encourage creative uses of communicative resources available to participants. Fourth, and finally, although not meant to be a serious activity, play frame can be used to negotiate social roles and norms, and to display identity claims.

The examples of code plays below are instances of collaboratively and spontaneously constructed online exchanges that share most of the features of playful talk identified in previous research. Hence, they might best be described as examples of bilingual online talk in a play frame. However, whereas research on play frames focuses mostly on the use of one code, the examples below involve playful manipulations of two or more codes. Creative employment of two or more codes for the purpose of humour is nothing unusual and has been documented in research (Woolard, 1988; Stølen, 1992; Siegel, 1995). However, most of the contexts analysed involve one individual producing well-crafted texts intended for staged offline performances such as songs and jokes. The examples of code plays below have emerged spontaneously and as a result of online collaboration. Furthermore, whereas previous studies on code switching in online and offline environments 
focused on insertions from one code to another, code plays involve manipulation and distortion of linguistic 'material', i.e. forms, patterns and rules of morphology, semantics and syntax of both codes. As a result, a type of a new code - a third code - is created which presents a unique blend of elements and rules underlying the codes available to users, and which might be difficult to understand even by bilingual speakers when taken out of the context of its use. In this sense, code plays might be seen as belonging to translanguaging space - a notion recently developed by $\mathrm{Li}$ (2011: 1234) to account for "the creative and critical use of multilingual resources by individual speakers in social interaction." As Li highlights, "[m]ultilingual speakers are not simply responding, rationally or not, to broader social forces and structures", but "through strategic use of the social resources, including linguistic resources" create interactionally spaces where they can fully display their multilingual identity. Drawing on Bhabba (1994), Li (2011) sees the translanguaging space as a kind of a third space where cultural translation between traditions takes place. Translanguaging space is not simply "a space where different identities, values and practices simply co-exist, but combine together to generate new identities, values and practices" ( $\mathrm{Li}$, 2011: 1223). This often involves a process of negotiation and rejection of the norms of the dominant (monolingual) language ideology. As identified by Li (2011), one of the linguistic practices, in which multilinguals engage when creating such spaces for themselves, is fun with words often involving the invention of funny nicknames. Since digital code plays involve more than fun with words, the notion can add another (online) dimension of playfulness to translanguaging space.

The last feature of digital code play which needs to be clearly spelt out is its essentially metalinguistic character (cf. Jaworski et al., 2004), which comes into view in two ways. Firstly, the way of how the CMC users play with the linguistic 'material' involves a high level of metalinguistic awareness in that they seem to see language as a system of forms, patterns and structures that are malleable and can be manipulated. In short, they have an awareness of language as an object, which, as research demonstrated, seems to be heightened in the case of bi- or multilinguals (Bialystok, 1986, 2001). Secondly, most of the code plays analysed below are triggered by explicit commentaries on language use and can be seen as a 'humorous take' on what Blommaert (1999) calls a language ideological debate (cf. Schieffelin, 1998). 
In the Anglo-German context, the ideological debate, in which the CMC users engage is the issue of the influence of English on the German language, especially the use of anglicisms. As Spitzmüller observes (2005: 261), this topic has become "one of the most intense folk-linguistic debates in the post-war Germany", which engaged a wide spectrum of society including media, politics, teachers and linguists. Given the confines of space, the historical roots and the current facets of the debate cannot be discussed in any depth (for research overviews see Langer and Davies, 2005; Pfalzgraf, 2006; Spitzmüller, 2005, 2007). For the context of this study, it might be sufficient to say that the German language and the process of its standardisation were the key elements in the process of nation building and the construction of the German identity in the $19^{\text {th }}$ century. Purist attitudes, which presume an existence of a homogenised national language with clearly defined boundaries, played a major role in this process. Influences from other languages, for example in form of borrowings or code mixing, are seen as language corruption, because they can potentially evade this purity. According to this perspective, languages have to be kept separated and cross-linguistic influences are generally objected. Since purism links standard national languages with national identity, influences from other languages are also seen as a threat to the national unity. The current language debate in Germany on the use of anglicisms has been dominated by purist attitudes which received quite a wide coverage, and in many instances, explicit endorsement from the media (Spitzmüller, 2005, 2007). In contrast, anti-purist voices seem to be mentioned in passing and side-lined. It is the dominating purist stance that the CMC users mock by flouting the linguistic norms underlying English and German. As demonstrated below, by creating humorous blends of both codes, the bilingual CMC users distance themselves from the dominating purist attitudes and, at the same time, ease the tensions that the debate tends to evoke.

\section{Research methods and data}

The data for the study were collected from a discussion forum Deutsche in London (DiL), used by German expatriates living in the UK. A discussion forum is an asynchronous online information platform where registered users can send and 
answer queries. It is normally divided into general categories (topics) and specific sub-topics (threads).

DiL is the largest and most active German-speaking discussion forum based in the UK and used by nearly 9,000 users. There are over 22,000 threads and more than 400,000 posts. Originally, the forum was created for Germans living in London, but over the past few years it has widened its scope and currently its membership includes many users outside the capital. The forum is moderated by an administrator and webmasters. There are a set of rules and regulations to follow when posting messages. The forum is divided into three main categories: general topics, life in Great Britain, and information for visitors. Each category includes a range of subcategories, which contain posts with threads. Judging from the topics discussed under the subcategory Jobs, most of the forum users are involved in administrative, professional or managerial occupations. There are also a number of users who are in education at different levels such as students or professionals seeking further training. For this reason, the users are referred to as expatriates, as this term is commonly used to denote migrants engaged in higher status occupations.

Normally, two main research designs are employed to examine language diversity and variation in CMC. Studies exploring the status of a particular variety and intensity of CS rely mainly on quantitative, statistical measures, for example word frequency lists (Siebenhaar, 2006, 2008). Research concerned with diverse functions of linguistic practices employs a range of qualitative methods such as Discourse Analysis, Online Ethnography or Conversational Analysis (Herring, 2004; Androutsopoulos, 2006, 2007, 2013; Themistocleous, 2013). Qualitative methods can shed light on a range of nuances and interesting, unusual patterns that a quantitative analysis cannot reveal. Since the current study is primarily concerned with functions of playful language alternation, it adopts a qualitative method of Computer-Mediated Discourse Analysis (CMDA) (Herring, 2001, 2004).

Section 4 presents examples of four exchanges taken from three longer 'discussions' that took place on the DIL forum. The selected discussions differed from other 'regular' forum exchanges in that they were not intended for exchange of information, which is, after all, the main function of a discussion forum. These 'other discussions' were not meant as sources of information but developed into bilingual plays or banters based on humorous exchanges in both codes, English and German. 
They attracted a large number of participants and contained unusual instances of language alternation. It was soon noted that exchanges involving a language 'issue', especially the influence of English on German, were particularly rich in examples of digital code plays. Thus, the decision was taken to analyse this type of metalinguistic online 'talk' in greater depth. Only threads that had a metalinguistic focus and generated longer discussions (more than 5 posts) were therefore considered. Longer threads contain many instances of digital code plays and are rich in examples demonstrating the variety of forms and functions of this linguistic practice. For the purpose of this paper, three threads with the total of 179 posts were analysed. Table 1 presents the topics of the selected threads and the number of posts in each.

Table 1: Data for the qualitative analysis

\begin{tabular}{l|r} 
Thread topic & $\begin{array}{r}\text { No. of } \\
\text { posts }\end{array}$ \\
\hline Gesucht: der schönste & 120 \\
Anglizismus & \\
(Wanted: the best anglicism) & \\
Germenglish & 44 \\
This is England & 15
\end{tabular}

The analysis of online exchanges followed the methodology of ComputerMediated Discourse Analysis (CMDA) (Herring, 2001, 2004). It was based on an examination of all posts in each thread and focused on the following aspects: the context of the textual exchanges, i.e. the user and his or her overall forum activity (normally measured by the number of posts), the purpose of the exchange, the topic development, and strategies of meaning negotiations. Instances of playful language alternations were identified and categorised in accordance with Warner's (2004) classification of play.

\section{Examples of digital code plays}

The exchanges discussed in this section serve to illustrate the diverse forms and functions of digital code plays. The analysis focuses first on the linguistic mechanisms involved in producing code plays, especially on the ways in which the rules of both English and German are violated and manipulated. Secondly, it 
tentatively demonstrates how such distortions and manipulations are playfully used to display participants' bilingual identities and to destabilise the ideology of language purity endorsed by the purist movement.

As the introduction highlights, some examples of language alternations detected in the DIL forum differ from the conventional notion of CS in that they involve playful manipulations of English and German and often develop into bilingual plays or banters. Extract 1, below, vividly illustrates such a play of wit.

\section{Extract 1:}

$1 \quad A[12: 20]^{2}$ : Ich möchte gerne einen Bekannten ärgern, der Anglizismen absolut nicht 2 ausstehen kann [...] Daher suche ich die schönsten Anglizismen....

3 I would like to annoy an acquaintance of mine who does not like anglicisms at all.

4 This is why I am looking for the most beautiful anglicisms...

$5 \quad B$ [13:02]: kommt das schnitzel mit jägersoße?

6 does the schnitzel come with a mushroom sauce?

7 C [13:08]: Da hast Du nen Punkt.

8 You've got a point here.

9 D [13:11]: Ja, gerade das "Schnitzel mit Jaegersosse" ist ein klassisches Beispiel 10 fuer Anglizismen

11 Yes, the "schnitzel with mushroom sauce" is a classic example of anglicisms

12 E [13:12]: Da nennt der Topf den Kessel schwarz...

13 And that's the pot calling the kettle black...

14 F [13:16]: Jaja, Frau Kontenfuehrungsleitkraft... :icon_mrgreen:

15 Yeah, yeah, Miss Accountant-Executive

16 E [13:27]: Wie war das nochmal, Herr Verkehrsberatungsingenieur...lch krieg die 17 Idee.

18 How was it again, Mr Traffic-Consultant-Engineer...I am getting the idea.

19 E [13:31]: Wir können ja auch Ideen voneinander abprallen

20 We can bounce ideas off each other

21 G [13:32]: Lass uns doch mal eine Gehirnsturmsitzung abhalten

22 Let's have a brainstorming session

23 E [13:33]: Ja, gerne, gib mir fuenf und dann bin ich mit Dir.

\footnotetext{
${ }^{2}$ The numbers in brackets indicate the time of posting.
} 
24 Yes, why not, give me five and I will be with you

In this dialogue, a fairly active forum user (User A with nearly 300 posts) begins a discussion thread in the section Allgemeines (general information). The intention is to collect the best anglicisms heard or used by the forum users in order to annoy a friend with a purist attitude (Line 1-2). In this initial query, the author of the thread does not only indicate distance from the purist stance. The overall tone might be interpreted as provocation. By using the superlative form of schön (beautiful) when referring to anglicisms, user $A$ evaluates the phenomenon positively and clearly mocks purist attitudes that often describe English insertions into German as ugly. The call initiated a series of responses that soon turned into playful exchanges based on transliterations, bilingual puns and plays with meanings of English and German words, phrases, and idioms. In response to A, User B (very active with over 2,000 posts) provides a sentence in which the use of the verb kommen (to come) is transferred from English creating unusual phraseology in German (Line 5). The combination of kommen with mit (with) is normally used to denote motion of people or animate objects. In this context, a German equivalent of to serve would be appropriate. The example is approved by the next user ( $\mathrm{C}$ - guest user); rather than using standard German, User C continues with this strategy and expresses approval with the statement Da hast Du nen Punkt, which is directly translated from the English you got a point here (Line 7). This is a play on the German equivalent $D u$ hast Recht (you are right), normally used in such a context. Although grammatically Da hast Du nen Punkt is correct, this statement is inappropriate for the situation because the noun Punkt (point) and the verb haben (to have) are not frequent collocations in German.

A few minutes later, another user comments on the example provided by $B$. User $D$ misunderstands the sentence, thinking that the anglicism was hidden in the phrase Schnitzel mit Jaegersosse (schnitzel with mushroom sauce) (Line 9-10). The next user (User E, over 1,700 posts) highlights the misunderstanding in an ironic way by literally translating the English proverb that's the pot calling the kettle black into German, so that the mode of code playing continues (Line 12). This rather ironic attitude expressed by User $E$ is disapproved of by User $F$ (over 2,200 posts), who joins in the conversation at this point. User F does not follow the strategy of direct 
translation and instead turns to the jargon commonly referred to as Beamtendeutsch (German official-ese), which is characterised by, among other things, nominal style and long compounds. Its use is associated with bureaucracy and pedantry. By calling User E Frau Kontenfuehrungsleitkraft (Ms/Mrs Accountant-Executive), F positions $E$ as a bureaucrat with somewhat pedantic attitude, but tones down the criticism by finishing the post with an emoticon which symbolises a big grin (Line 14). The use of Frau (Ms/Mrs), which is a form of addressing women in formal situations, marks here a register shift from informal to formal. However, the formality is intended as play; although the term used here complies with the rules of compounding in German, the profession of Kontenfuehrungsleitkraft does not exist in German and the word is a pure creation of user $F$. User $E$ immediately responds in the same Beamtendeutsch formal mode by referring to $\mathrm{F}$ with a long compound Verkehrsberatungsingenieur (Traffic-Consultant-Engineer) and addressing $\mathrm{F}$ as Herr (Mr) (Line 16), which again is morphologically correct, but as such does not exist in German. User E, then, returns to the code-playing mode by finishing the post with the statement Ich krieg die Idee (I am getting the idea) (Line 16). Here again, the combination of the verb kriegen (to get) with the noun Idee (idea) does not occur in German and the phrase is a literal translation from English. A few minutes later, user E tones down the formality evoked through the use of the German official-ese and the terms of address Frau (Ms) and Herr (Mrs) by inviting $\mathrm{F}$ to collaboratively generate some new ideas, as signalled by the plural personal pronoun wir (we) - Wir können ja auch Ideen voneinander abprallen (We can bounce ideas of each other) (Line 18). The literal translation of the English collocation bounce ideas of each other is unusual for German, as abprallen (bounce) is normally used with concrete objects and refers to a physical movement. Extending its use to abstract concepts such as the noun idea generates a comical effect. This jocular mode based on direct translations from English into German turned out to be the default choice for most of the discussion, which continued throughout six months, generating a total of 120 posts.

Apart from keeping up the exchanges in this particular mode, there are also occasional reports of self-use of such anglicized jargon in the offline world (see Extract 2 taken from the same thread). 


\section{Extract 2:}

1 G [15:07]: Ich hatte neulich eine Erkaeltung - my ears were popping. Sage ich also

2 zur deutschen Kollegin: "Meine Ohren poppen dauernd". :icon_redface:

3 Recently, I've had a cold - my ears were popping. So I said to a German colleague:

4 "my ears are popping all the time".

$5 \quad H$ [18:23]: :icon_mrgreen: no comment

6 A [08:25]: Na, das ist doch ein Rezept für Desaster

7 Yeah, that's a recipe for a disaster

8 (one of the last posts in the thread some days later)

9 J [07:44]: absolut hilariös :icon_mrgreen:

10 absolutely hilarious

While in extract 1 the humorous effect emerges organically (cf. Coates, 2007) as a by-product of the spontaneous exchanges of turns in German, Extract 2 is a good example of the use of code mixing for the purpose of telling jokes directly. Here, User G (nearly 1,200 posts) tells a story which is seen as embarrassing (marked by the icon redface), but which is, at the same time, very funny (Line 1-2). The twist is based on the use of the English verb to pop, which was literally translated into German as poppen. The verb exists in German, but has a very different meaning. It is a colloquialism, which describes sexual intercourse. This, in connection with Ohren (ears), generates a comical effect (Line 2). The funny reading of the story is foregrounded as indicated by the response of User $\mathrm{H}$ (over 200 posts), who comments on the story with a big grin and the English insertion no comment (Line 5). User A (who started the thread) joins in and signals the humorous understanding by reverting to the preferred mode of the discussion. The statement $\mathrm{Na}$, das ist doch ein Rezept für Desaster (that's a recipe for a disaster) is again a direct translation from English (Line 6). Some days later, User $\mathrm{J}$ comments on the exchange in a jocular way by using the word hilarious transliterated in German as hilariös and a big grin at the end of the post (Line 9).

The two extracts demonstrate that the forum users draw playfully on both codes English and German to engage in humorous bilingual exchanges. While we find here instances of conventional CS, these exchanges are mostly based on conscious manipulation and violation of both codes available to the users. The users play with 
forms at all levels (transliterations, bilingual punning, long compounds and the use of emoticons) as well as with meanings (semantic plays, e.g. Meine Ohren poppen dauernd). They consciously flout the linguistic and semantic conventions of the target and their first language to create a type of a third code - an extremely anglicised jargon that purists would clearly find non-acceptable or even a threat to the German identity (Spitzmüller, 2005, 2007). By mixing both codes at all levels and creating humorous turns in this anglicised jargon, the participants put paid to purist concerns. This is further supported by the fact that such extreme code mixing does not necessarily invite negative comments. Only 5 out of 120 posts contain some expressions of disapproval. This, in turn, indicates that for the active forum users, language mixing is a natural phenomenon and a practice in which they engage on a regular basis, as many of the self-use reports indicate. Furthermore, the exchanges analysed here have a strong performative character, as they rapidly develop into a playful competition of wit. In the offline world such verbal plays are normally reserved for staged performances such as comedy shows or joke-capping sessions. In contrast to the offline reality where bilingual puns and jokes are often carefully grafted or passed from generation to generation (Woolard, 1988; Siegel, 1995), the online exchanges analysed here are spontaneous, although it needs to be borne in mind that the CMC users have time for thought and editing. Although for the most part meaningless in German, the turns are understood as funny by the members of this online community. Thus, the humorous anglicised talk in German co-constructed by the users appears to create group solidarity in this online community (Coates, 2007). Similar to the participants studied by Tagg and Seargeant (2012), the German expatriates align themselves to each other not only because they speak both languages and live in the UK, but also because they playfully deploy the linguistic and other semiotic resources available to them. Through such violation of linguistic rules at all levels, these participants not only aim to achieve a comic effect, though at first glance this seems to be the main purpose. They also demonstrate their advanced bilingual competence and creativity. Furthermore, and similar to the practice of bricolage or hyperdialectism discussed by Tsiplakou and loannidou (2012), this kind of linguistic violation serves to destabilise the ideological notion of language purity endorsed by the purist movement (Pfalzgraf, 2006; Spitzmüller, 2005, 2007) 
However, the topic of mixing the two languages seems to be a recurrent issue, often directly addressed as the title of the thread Germenglish shows. It was started by a user who was new to this community. In the opening statement, user $\mathrm{K}$ openly expresses distaste for language mixing (see Extract $3 \mathrm{~A}$ ).

\section{Extract 3A:}

$1 \quad \mathrm{~K}$ [12:13]: Beim Lesen vielen Beiträge fällt mir immer wieder auf, wie oft doch unsere

2 Muttersprache von vielen Boardmembers mit dem Englischen vermischt wird. [...] da

3 ich relativ neu hier am Start bin, wuerde mich mal die Meinung der Peoples dazu

4 interessieren. Ich persoenlich finde es eher unpleasant.

5 Reading some of the posts here, it strikes me how often forum users mix our mother

6 tongue with English. Since I am new here, I am interested in what people think about

7 it. Personally, I find it rather unpleasant

Although User K objects to code-mixing on aesthetic grounds: Ich persoenlich finde es eher unpleasant (Line 4: Personally, I find it rather unpleasant), $\mathrm{K}$ makes use of English switches, perhaps because he/she wants to be a bit provocative. The prompt generated 44 answers in which most of the users did not share the view expressed by $\mathrm{K}$. Some of them responded in an ironic way, while others took it as an opportunity to code play (Extract 3B).

\section{Extract 3B:}

1 L [12: 39]: ich finde, englisch sollte in diesem forum verboten werden. nein, besser:

2 englisch sollte überhaupt verboten werden. weltweit. das wär ein spaß.

3 findet $L$ sprach-taliban

4 I think English should be forbidden in this forum. No, even better: English should be

5 forbidden full stop. worldwide. that would be fun, I think $L$ Language-Taliban.

$6 \quad$ M [12: 58]: Oh mei gudniss, off kurs ich verwende inglische Wörter tu sho off.

7 Ich kann mir ehrlich gesagt nicht vorstellen, dass man in einem mittelfristigen

8 Zeitfenster (ca. 5 bis 10 Jahre) seine eigene Mutterzunge verlernt. In diesem Sinn,

9 God shave the Königin und Sprach-Taliban L! 
10 Oh my goodness, of course I use English words to show off. I cannot imagine that 11 someone would forget his/her mother tongue within the space of 5 to 10 years.

12 Having said this, God shave the Queen and Language-Taliban L!

In response to $\mathrm{K}$, a very active User $\mathrm{L}$ (over 2,000 posts) mocks the debate by suggesting a complete ban on English worldwide (Line 1-3). This is an ironic take on the purist stance expressed by $\mathrm{K}$ and implies that it is rather absurd to think that the influence of English could be stopped. A few minutes later, another user (User M, nearly 1,000 posts) joins in and begins with a statement in which she/he mixes English and German. M diverts from the English spelling and transliterates most of the English words by adopting German orthography or mixture of both, for example gudniss (goodness) or off kurs (of course). This seems to be done purposefully to amplify the message and to perhaps annoy $\mathrm{K}$, who claims to find language mixing unpleasant. After the first sentence, $M$ switches to standard German, which contrasts sharply with the previous statement (Line 7-8). With this switch, M probably intends to place stronger emphasis on the fact that language mixing does not lead to the loss of the mother tongue. At the end, $\mathrm{M}$ reverts again to English and quotes from a parody of the English national anthem (Line 9). The use of humorous CS to conclude might be seen as an attempt to tone down the provocation expressed at the beginning of the post (cf. Norrick and Spitz, 2008).

These examples of code plays are mostly triggered by comments concerned with the influence of English on German. As Extract 4 shows, more specific issues of language use can also prompt the users to play with both codes. The example below is an extract from a shorter thread entitled This is England (15 posts in total), which was posted in the section Essen (food).

\section{Extract 4:}


$1 \quad \mathrm{~N}$ [17:42]: Hilfe! Habe gerade im Kuehlschrank Magnum Mint entdeckt.... Wer isst 2 sowas?!? :icon_eek: :icon_mrgreen:

3 Help! I have discovered Magnum Mint in the fridge ... Who eats stuff like that?!?

4 O [17:45]: Kannst ja 'ne Spycam vorm Fridge aufbauen. Wirste dann ja schon sehen. 5 :icon_wink:

6 You can install a spy camera in front of the fridge. Then you'll find out.

$7 \quad P$ [17:52]: Ist das nicht "die" Fridge?

8 Is it not the [feminine] fridge?

9 R [18:03]: :icon_biggrin: nee O. man sagt doch nicht "die kuehlschrank"!

10 No User $O$. we don't say the [feminine] fridge

$11 S$ [18:24] in response to P: Durchsuchst du jetzt das ganze Forum nach "Grammatik 12 Fehlern"? :icon_warumnur:

13 Are you searching now for grammar mistakes in the whole forum? :icon_why:

14 P [18:27]: nee, eher nach unnoetigen anglizismen :icon_smoke:

15 No, only for unnecessary anglicisms

16 [18:32]: Get a life, mate!

$17 \mathrm{P}$ [18:44]: Take it easy, ich wollte dir doch nur eine(n) Nudge geben :icon_wink:

18 Take it easy, I just wanted to give you a nudge: :icon_wink:

$19 \mathrm{Q}$ [20: 40]: Ich liebe Mint Magnum. Gibts aber doch schon laenger hier

20 I love Mint Magnum. It has been around for some time now

User $\mathrm{N}$ (over 300 posts) starts the thread with a request for help. $\mathrm{N}$ discovered a mint ice cream (something not very popular in Germany) in the fridge and is obviously astonished that such ice cream exists (Line 1-2). The astonishment is here emphasised by the use of the emoticon icon_eek. User O (very active; nearly 2,000 posts) joins in and suggests that $\mathrm{N}$ should install a camera in front of the fridge in order to find out who likes this kind of ice cream (4-5). The next user (User $P$, over 600 posts) diverts from the actual topic of the conversation and shifts to a metalinguistic level by querying the grammatical gender allocated to the word fridge by $\mathrm{O}$ (Line 7). User $\mathrm{P}$ suggests the use of the feminine article die, but this is rejected by the next user who points to the gender of the German equivalent Küh/schrank 
(Line 9). ${ }^{3}$ User S, who joins in at this point, seems to be puzzled by the turn of the conversation initiated by $\mathrm{P}$ and the somewhat picky attitude. The question posed by $S$ - Are you searching now for grammar mistakes in the whole forum? - points to the futility of such an exercise (Line 11-12). In response, $P$ asserts the view that the use of anglicisms is unnecessary. User $\mathrm{O}$, who suggested the installation of a spy camera at the beginning of the thread, seems now to be irritated by $P$ and switches completely to English. The use of the imperative Get a life mate is a direct attack on P's comments (Line 16). To mitigate the tension, $\mathrm{P}$ adopts the bilingual mode and responds with the English phrase Take it easy. User $\mathrm{P}$ then continues the post with code playing based on the literal translation of the English phrase 'to give someone a nudge', but uses two gender options with Nudge to perhaps create distance from his/her previous comments (Line 17). This is possibly to indicate that the responses should not be taken too seriously and that the intention was not to create a conflict situation. This is further emphasised by the use of the emoticon icon_wink to conclude the post. In this way, tension was resolved and the conversation continued on-topic (Line 19). This exchange is a good example to demonstrate that the issue of the influence of English on German is a contentious issue and can lead to a conflict situation. Code play by means of transliterations and play with meanings were used here as a strategy to ease out the tension and to re-establish harmony in the conversation. In this way, digital code plays can be used, similarly to CS, as a device for the management of online 'talk'. Yet, and at the same time, they are more than this. By competently translating English phrases into humorous turns in German, the participants enact, performatively, their competent bilingual identity, manifested in a heightened metalinguistic awareness and the ability to mix two codes in a playful way at all language levels. Moreover, by producing such anglicised or 'polluted' German, the participants dismantle the ideology of language purity, and thereby put paid to purist concerns.

\footnotetext{
${ }^{3}$ The German equivalent of fridge is Kühlschrank and it is a masculine noun. User $\mathrm{O}$ probably transferred the masculine gender to the English noun, which is indicated by the use of the article dem in the dative case contracted with the preceding preposition vor (in front of) to form vorm. Dem can also mark neuter nouns in the dative case.
} 


\section{Discussion}

The current study analysis has shown that in the CMC context under, bilingual users engage in co-constructions of playful language alternation that differ from the conventional notion of code switching. The instances of creative and playful language mixing analysed above are of a different kind, and most occur in contexts beyond the ostensible transactional purpose of the forum, namely, in threads and posts prompted by metalinguistic references.

As demonstrated in Extracts 1 and 2, the forum users deploy their linguistic and other semiotic resources for the co-construction of humorous exchanges in aberrant anglicised German. These are predominately based on conscious manipulation and distortions of both codes and have been referred to as code plays. Similar to the exchanges analysed by Coates (2007: 31$)$, the virtual interactions above can be seen as examples of "spontaneous outbursts of play" emerging organically.

Paraphrasing the title of her paper "Talk in a play frame", they can be described as a virtual talk in a play frame. Essential for the establishment of a play frame in a conversation is participants' collaboration. The examples discussed demonstrate that this is also the case in virtual environments. Extract 1 shows that the users eagerly participate in the construction of the anglicised turns in German with the exchanges following quickly one after the other. Some of the discussions continued in this mode for many weeks. Although to some extent the medium constraints participation - only one user can join at a time - given the continuation of exchanges and the preferences for the anglicised German, there is a strong sense of playful collaboration. Given the technological constraints of the medium, we do not find here examples of two other features of playful talk as identified by Coates (2007), namely overlapping speech and repetitions. These are features typical for speech and cannot be expected in a medium which is essentially written. At the same time, the users compensate for the lack of forms of expressions typical for speech by using a range of graphical signs; for example, laughter - one of the five elements of a playful talk (Coates 2007) - is signalled by the very frequent use of the icon biggrin or mrgreen.

The most striking feature of code plays in the exchanges analysed in this current study are the conscious distortions and manipulations of two codes, English and 
German. Similar to the online exchanges examined by Warner (2004), the forum users play with English and German at all language levels. In the data, we find numerous instances of play with forms involving German transliterations of English words and phrases (e.g. hilariös, oh mei gudniss) or long compounding (Gehirnsturmsitzung, Herr Verkehrsberatungsingenieur). The most dominant form of play was, however, the semantic play based on direct translations of English proverbs, idioms or other colloquial expressions into German. Finally, there are also examples of play with a frame. As shown in Extract 1, humorous turns may develop into a competition of wit - a format adopted normally in comedy shows. While in the off-line reality jokes for such shows are normally carefully grafted and can be understood "away from the context" in which they were performed (Coates, 2007: 31 ), here the humour is generated spontaneously and it would be difficult to understand it outside of this particular play frame. Hence, such online exchanges might best be described as strongly contextualised performances, in the sense of Bauman (1975) in which the main action is play with codes for the purpose of humour and entertainment. Most of the exchanges conducted in this mode would be meaningless or perhaps odd for a monolingual German speaker or even a bilingual English-German speaker. However for the forum users, the exchanges are understood and considered funny.

One of the interesting but perhaps unsurprising facts emerging from this current study is that code plays are essentially triggered by comments or queries of a metalinguistic nature. All of the analysed instances were responses to an issue involving the use of English insertions in German. This has been a hotly debated topic since the reunification of both German states in 1989 underpinned by tensions and polarised views. Essentially, the debate was dominated by purist views that see the use of anglicisms as a threat to the German language and identity, and hence, call for laws to regulate the use of foreign words (Spitzmüller, 2005, 2007). By using code plays, the bilingual CMC users reject the purist attitudes thereby. In doing so, they not only express their critical attitude towards this debate. When consciously flouting the linguistic conventions of both English and German, they display their heightened metalinguistic awareness, so typical for bilinguals, and demonstrate their bilingual creativity and criticality (in the sense of Li, 2011). In this way, code plays can be seen as one of the mechanisms creating a translanguaging (virtual) space. 


\section{Conclusion}

The point of departure for this study was the observation that the affordances of the medium - the Internet - offers new opportunities that CMC users exploit in creative and sophisticated ways (Barton and Lee, 2013). The kind of digital code plays demonstrated above occur very rarely in bilingual offline conversations, and mostly in the context of staged performances. However, in the discussion forum they become salient features of online exchanges in the context of negotiating or contesting language norms. This is not to say that digital code plays are mediumdriven, but they are certainly medium-specific (Tsiplakou, 2009). It is, after all, this virtual environment, which offers time and space for the development and use of this linguistic practice. At first sight it might appear that digital code plays are used mainly for a comic effect; yet there is more to digital code play than just humour. Given that digital code plays occur mostly in the context of a language ideological debate, specifically the issue surrounding the English influence on German, they are also playful means of conveying metalinguistic discourse on the forum, and participants' attitudes towards this debate. By mixing both codes at all levels in a humorous way, the participants deliberately produce a third code - aberrant German 'polluted' with English and in so doing, dismantle the ideology of language purity upheld by the purist movement and the related notion of double monolingualism. The deliberate and conscious character of this type of code mixing demonstrates bilingual creativity and criticality and as a practice of networked multingualism can be seen as evidence for processes associated with poly- and metrolingualism (Androutsopoulos, 2013).

The current study examined playful language alternation only in one forum and was based on a relatively small sample. Further work with a larger sample needs to be conducted to establish (1) whether there are other forms and functions of digital code play(s) developed by different bi- or multilingual communities in $\mathrm{CMC}$, and (2) evaluate what factors facilitate or constrain the development of this linguistic practice. It would be especially interesting to investigate whether code plays are prompted solely by metalinguistic comments or whether there are other triggers. Further research in this area would also benefit from adopting an ethnographic 
approach to investigate insiders' attitudes towards language mixing on the Internet and specifically the use of code plays.

\section{References}

Androutsopoulos, Jannis, 2006. Multilingualism, diaspora, and the Internet: codes and identities on German-based diaspora websites. Journal of Sociolinguistics 10 (4), 429-450.

Androutsopoulos, Jannis, 2007. Language choice and code-switching in Germanbased diasporic web forums. In: Danet, B., Herring, S. (Eds.), The Multilingual Internet. Oxford University Press, Oxford, pp. 340-361.

Androutsopoulos, Jannis, 2013. Networked multilingualism: Some language practices on Facebook and their implications. International Journal of Bilingualism, published online 11 June 2013, 1-21.

Androutsopoulos, Jannis, Hinnenkamp, Volker, 2001. Code-Switching in der bilingualen Chat-Kommunikation: ein explorativer Blick auf \#hellas und \#turks. In: Beißwenger, M. (Ed.), Chat-Kommunikation. Ibidem, Stuttgart, pp. 367-402.

Auer, Peter (Ed.), 1998. Code-Switching in Conversation. Language, Interaction and Identity. Routledge, London.

Aukrust, Vibeke, 2004. Explanatory Discourse in Young Second Language Learners' Peer Play. Discourse Studies 6 (3), 393-412.

Barton, David, Lee, Carmen, 2013. Language Online. Investigating Digital Texts and Practices. Routledge, London and New York.

Bateson, Gregory, 1972. A theory of play and fantasy. Steps to and ecology of mind. Ballantine, New York.

Bauman, Richard, 1975. Verbal art as performance. American Anthropologist 77, 290-311.

Belz, Julie, Reinhardt, Jonathon, 2004. Aspects of advanced foreign language proficiency: Internet-mediated German language play. International Journal of Applied Linguistics 14 (3), 324-362.

Bhabba, Homi, 1994. The Location of Culture. Routledge, London.

Bialystok, Ellen, 1986. Children's concept of word. Journal of Psycholinguistic Research 15 (1), 13-32. 
Bialystok, Ellen, 2001. Bilingualism in Development: Language, Literacy, and Cognition. Cambridge University Press, Cambridge.

Blommaert, Jan (Ed.), (1999). Language ideological debates. Mouton de Gruyter, Berlin.

Chiaro, Delia, 2009. Cultural divide or unifying factor? Humorous talk in the interaction of bilingual, cross-cultural couples. In: Norrick, N. R., Chiaro, D. (Eds.), Humor in Interaction. Benjamins, Amsterdam/Philadelphia, pp. 211-231.

Coates, Jennifer, 2007. Talk in a play frame: more on laughter and intimacy. Journal of Pragmatics 39 (1), 29-49.

Cook, Guy, 2000. Language Play, Language Learning. Oxford University Press, New York.

Davies, Catherine, 2003. How English-learners joke with native speakers: an interactional sociolinguistic perspective on humour as collaborative discourse across cultures. Journal of Pragmatics 35 (9), 1361-1385.

Dürscheid, Christa, 2004. Netzsprache - ein neuer Mythos. In: Beißwenger, M., Hoffmann, L., Storrer, A. (Eds.), Internetbasierte Kommunikation. Osnabrücker Beiträge zur Sprachtheorie 68, pp. 141-157.

Georgakopoulou, Alexandra, 1997. Self-presentation and interactional alliances in email discourse: the style- and code-switches of Greek messages. International Journal of Applied Linguistics 7 (2), 141-164.

Goffman, Erving, 1974. Frame analysis: An essay on the organization of experience. Harvard University Press, Cambridge.

Herring, Susan, 2001. Computer-mediated discourse. In: Schiffrin, D., Tannen, D., Hamilton, H. (Eds.), The Handbook of Discourse Analysis. Blackwell, Malden, pp. 612-634.

Herring, Susan, 2004. Computer-mediated discourse analysis: an approach to researching online communities. In: Barab, S., Kling, R., Gray, J. (Eds.), Designing for Virtual Communities in the Service of Learning. Cambridge University Press, Cambridge/New York, pp. 338-316.

Hinrichs, Lars, 2006. Codeswitching on the Web: English and Jamaican Creole in Email Communication. Benjamins, Amsterdam/Philadelphia.

Jaworski, Adam, Coupland, Nikolas, Galasiński, Dariusz, 2004. Metalanguage:

Social and Ideological Perspectives. Walter de Gruyter, Berlin. 
Jørgensen, J. Normann, 2008. Polylingual languaging around and among children and adolescents. International Journal of Multilingualism, 5 (3), 161-176.

Langer, Nils, Davies, Winifred (Eds.), 2005. Linguistic Purism in the Germanic Languages. Walter de Gruyter, Berlin.

$\mathrm{Li}$, Wei, 2011. Moment Analysis and translanguaging space: Discursive construction of identities by multilingual Chinese youth in Britain. Journal of Pragmatics 43, 1222-1235.

Li, Wei, Milroy, Lesley, Pong, Sin Ching, 1992. A two-step sociolinguistic analysis of code-switching and language choice. International Journal of Applied Linguistics 2 (1), 63-86.

Lytra, Vally, 2007. Play frames and social identities: Contact encounter in a Greek primary school. John Benjamins, Amsterdam.

Matras, Yaron, 2009. Language Contact. Cambridge University Press, Cambridge.

Norrick, Neal, R., Spitz, Alice, 2008. Humor as a resource for mitigating conflict in interaction. Journal of Pragmatics 40 (10), 1661-1686.

Otsuji, Emi, Pennycook, Alastair, 2010. Metrolingualism: Fixity, fluidity and language in flux. International Journal of Multilingualism, 7 (3), 240-254.

Paolillo, John, 1996. Language choice on soc-culture.punjab. Electronic Journal of Communication 6, http://ella.slis.indiana.edu/ paolillo/research/paolillo.publish.txt [last accessed 21 February 2012].

Pfalzgraf, Falco, 2006. Neopurismus in Deutschland nach der Wende. Peter Lang, Frankfurt am Main.

Schieffelin, Bambi, Woolard, Kathryn, Kroskrity, Paul, (Eds.). 1998. Language Ideologies: Practice and Theory. Oxford University Press, New York.

Siebenhaar, Beat, 2006. Code choice and code-switching in Swiss-German Internet relay chat rooms. Journal of Sociolinguistics 10 (4), 481-506.

Siebenhaar, Beat, 2008. Quantitative approaches to linguistic variation in IRC: Implications for qualitative research. Language@Internet 5, http://www.languageatinternet.org/articles/2008/1615 [last accessed 21 February 2012]

Siegel, Jeff, 1995. How to get a laugh in Fijian: Code-switching and humour. Language in Society 24, 95-110. 
Spitzmüller, Jürgen, 2005. Metasprachdiskurse. Einstellungen zu Anglizismen und ihre wissenschaftliche Rezeption. Mouton de Gruyter, Berlin.

Spitzmüller, Jürgen, 2007. Staking the claims of identity: Purism, linguistics and the media in post-1990 Germany. Journal of Sociolinguistics 11 (2), 261-285.

Stølen, Marianne, 1992. Codeswitching for humour and ethnic identity: Written Danish-American occasional songs. Journal of Multilingual and Multicultural Development 13 (1/2), 215-28.

Su, Hsi-Yao, 2007. The multilingual and multiorthographic Taiwan-based internet: Creative uses of writing systems on college-affiliated BBSs. In: Danet, B., Herring, S. (Eds.), The multilingual Internet: Language, culture, and communication online. Oxford University Press, Oxford, pp. 64-86.

Tagg, Caroline, Seargeant, Philip, 2012. Writing systems at play in Thai-English online interactions. Writing Systems Research, 4 (2), 195-213.

Themistocleous, Christiana, 2013. Digital code-switching between Cypriot and Standard Greek: Performance and identity play online. International Journal of Bilingualism (in press).

Tseliga, Theodora, 2007. "It's all Greeklish to me!" Linguistic and sociocultural perspectives on Roman-alphabeted Greek in asynchronous computer-mediated communication. In: Danet, B., Herring, S. (Eds.), The multilingual Internet: Language, culture, and communication online. Oxford University Press, Oxford, pp. 116-141.

Tsiplakou, Stavroula, 2009. Doing (bi)lingualism: language alternation as performative construction of online identities. Pragmatics 19, 361-391.

Tsiplakou, Stavroula, loannidou, Elena, 2012. Stylizing stylization: The case of Aigia Fuxia. Multilingua 31, 277-299.

Warner, Chantelle, 2004. It's just a game, right? Types of play in foreign language CMC. Language Learning \& Technology 8 (2), 69-87.

Woolard, Kathryn, 1988. Codeswitching and comedy in Catalonia. In: Heller, M. (Ed.), Codeswitching: Anthropological and Sociolinguistic Perspectives. Mouton de Gruyter, Berlin, pp. 53-76. 